\title{
Proteomic identification of target proteins following Drosha knockdown in cervical cancer
}

\author{
JUN ZHOU* ${ }^{*}$, JING CAI ${ }^{*}$, ZAIJU HUANG, HUI DING, JUNJIE WANG, JINGHUI JIA, \\ YONG ZHAO, DA HUANG and ZEHUA WANG \\ Department of Obstetrics and Gynecology, Tongji Medical College, Union Hospital, \\ Huazhong University of Science and Technology, Wuhan, Hubei, P.R. China
}

Received May 13, 2013; Accepted June 26, 2013

DOI: $10.3892 /$ or.2013.2672

\begin{abstract}
The nuclear microRNA (miRNA) processing enzyme Drosha is upregulated in cervical cancer, and its overexpression is related to an invasive tumour phenotype. However, the mechanisms that underlie this effect remain poorly understood. The aim of this study was to identify the potential targets of Drosha in cervical cancer. Here, we demonstrated that Drosha knockdown (Drosha-KD) inhibited proliferation, colony formation and the migration of cervical cancer cells in vitro. A global upregulation of proteins in Drosha-KD cells was revealed by two-dimensional gel electrophoresis (2-DE). Eighteen proteins were identified by liquid chromatography and tandem mass spectrometry technology (LC-MS/MS) from 21 selected protein spots that exhibited significant alterations in Drosha-KD cells. The majority of the identified proteins have been previously associated with tumour formation. The downregulation of tubulin $5 \beta$ in Drosha-KD cervical cancer cells was further confirmed by western blotting. Our results suggest that Drosha affects the biological activity of cervical cancer cells by regulating the expression of numerous tumourassociated proteins.
\end{abstract}

\section{Introduction}

microRNAs (miRNAs) are non-coding single-stranded RNA molecules that are 21-25 nucleotides in length and primarily function as negative gene regulators (1). miRNAs are involved in several key biological phenomena, including cell differentiation, proliferation and apoptosis. There is increasing evidence that miRNAs play an important role in cancer development $(2,3)$. During miRNA genesis, polymerase II transcribes

Correspondence to: Professor Zehua Wang, Department of Obstetrics and Gynecology, Tongji Medical College, Union Hospital, Huazhong University of Science and Technology, 1277 Jiefang Dadao Road, Wuhan, Hubei 430022, P.R. China

E-mail: zehuawang@163.net

*Contributed equally

Key words: cervical cancer, Drosha, proteomics an immature form of miRNA that is referred to as pre-miRNA. This type of miRNA is potentially as long as thousands of base pairs and contains both a 50-cap and a (poly)A tail (4). Following the generation of the pri-miRNAs, two enzymes play pivotal roles in the processing of these transcripts: Drosha (RNASEN) and Dicer (DICER1). Drosha, a nuclear enzyme, cuts pre-pri-mRNA segments into short double-stranded RNA precursors, which are referred to as pre-miRNAs, that have an approximate length of 60-70 nucleotides (5). The pre-miRNAs are then cleaved in the cytoplasm by Dicer into mature doublestranded miRNA fragments that are each $~ 15-30$ nucleotides in length $(6,7)$.

Drosha overexpression occurs frequently in cervical cancer (8-10) and is associated with substantial differences in miRNA profiles (11). However, the effects of Drosha dysregulation on the proteomic profile of cervical cancer cells following changes in their miRNA expression profile are unknown.

Here, we used gene depletion experiments to demonstrate that altered Drosha levels in cervical cancer cell lines caused significant changes in the cellular phenotype and the global differential expression of proteins in vitro.

\section{Materials and methods}

Cell culture. The following cervical cells were used: i) three independent primary cultures of normal cervical epithelial cells (12); ii) the normal cervical epithelial cell line CRL2614 that was obtained from ATCC; and iii) three cervical cancer cell lines HeLa, SiHa and C33a, which were purchased from the China Center for Type Culture Collection (CCTCC), Wuhan University, China. Standard protocols for cell culture were used $(13,14)$. The specimen collection and archiving of patient data were performed with written informed consent and were approved by the Ethics Committee of the Wuhan Union Hospital.

RNA interference (RNAi) and stable transfection. Four shRNAs (shDro homo 1614/570/1948/2936; GenePharma, Shanghai, China) targeting Drosha were generated. Their target sequences were as follows: shDro homo 1614, 5'-GGGA GATTCTACAGTGGTTGG-3'; shDro homo 570, 5'-GCAGC CTCCTGTGCAATATCA-3'; shDro homo 1948, 5'-GCAAGA CGCACAGGAATTAGG-3'; shDro homo 2936, 5'-GCTACC 
ACCAATGCCTAATCG-3'; and the negative control (shNC) 5'-GTTCTCCGAACGTGTCACGT-3'. The transfections were performed using Lipofectamine 2000 reagent (Invitrogen, USA). Geneticin (G418) selection was performed $24 \mathrm{~h}$ following transfection for $48 \mathrm{~h}$ at $800 \mathrm{ng} / \mathrm{ml}$. The efficiency of transfection was evaluated by observing the green fluorescence under an inverted fluorescence microscope (Olympus, Japan), and the knockdown efficiency was assessed at the mRNA level $72 \mathrm{~h}$ post-transfection.

For stable Drosha depletion, recombinant Lenti-virus (GenePharma) was used to deliver shDro homo 2936 shRNA (Lenti-shDro). GFP and anti-puromycin genes were incorporated into this vector to permit the convenient monitoring of the infection efficiency under the fluorescence microscope and screening of the uninfected cells. The cervical cancer cells were seeded into 6 -well plates (cell line-dependent). The virus was added into the medium at a MOI of 10 and co-cultured for $24 \mathrm{~h}$. The cells that were transduced with Lenti-shDro were screened using $2 \mu \mathrm{g} / \mathrm{ml}$ puromycin.

RNA isolation and quantitative real-time PCR ( $q R T-P C R)$. Total RNA was isolated from cells using the TRIzol reagent (Invitrogen, USA), and complementary DNA was synthesised using a reverse transcription kit (Toyobo, Osaka, Japan) according to the manufacturer's protocol. The sequences of the primers for Drosha mRNA detection were the following: forward, 5'-CATGTCACAGAATGTCGTTCCA-3'; and reverse, 5'-GGGTGAAGCAGCCTCAGATTT-3'. The PCR was performed on an ABI StepOnePlus thermocycler (Applied Biosystems, USA) using the SsoFast EvaGreen Supermix with Low ROX (Bio-Rad, USA). The amplification protocols were as follows: $95^{\circ} \mathrm{C}$ for $30 \mathrm{sec}$ followed by 40 cycles of $95^{\circ} \mathrm{C}$ for $5 \mathrm{sec}$ and $59^{\circ} \mathrm{C}$ for $30 \mathrm{sec}$. After the PCR, a melting curve was constructed by increasing the temperature from 65 to $95^{\circ} \mathrm{C}$ with a temperature transition rate of $0.2^{\circ} \mathrm{C} / \mathrm{sec}$. Each sample was analysed in triplicate. The Drosha transcript level was normalised to the $\beta$-actin amplification level and was calculated using the comparative threshold cycle $(\mathrm{Ct})$ method $\left(2^{-\Delta \Delta C t}\right)$.

Western blotting. SDS-PAGE and western blotting were performed as previously described (16). Briefly, the total protein in each sample was subjected to Tris-glycine SDS-PAGE separation. After protein transfer, PVDF membranes were incubated with a Drosha rabbit antibody (D30F3, 1:1,000; Cell Signaling Technology, USA) or a tubulin $5 \beta$ mouse polyclonal antibody (ab52837, 1:1,000; Abcam, USA) followed by incubation with an HRP-conjugated secondary antibody (Amersham Biosciences). The protein levels were visualised using the ECL substrate kit (Amersham Biosciences). The protein expression of $\beta$-actin was used as an internal control.

Wound-healing assay. Between 0.6 and $1.2 \times 10^{6}$ cells (cell line-dependent) were seeded into 6-well plates, the undersurfaces of which were marked with a horizontal line along the diameter, in $2 \mathrm{ml}$ of DMEM with $10 \%$ fetal calf serum (both from HyClone, USA). Twenty-four hours later, three parallel scratches, perpendicular to the horizontal line, were made in the monolayer using a pipette tip. The width of the scratches was measured over the following $24 \mathrm{~h}$ at three fixed distances from the line, and the mean values were used to quantify wound healing.

Cell invasion assay. Between 2 and $4 \times 10^{3}$ transfected cells (cell line-dependent) were seeded per well of an 8- $\mu \mathrm{m}$ Growth Factor-Reduced invasion chamber (BD Biosciences, Oxford, UK) in $1 \mathrm{ml}$ DMEM without serum. One milliliter of the DMEM (20\% FBS) was added below the chamber. Invasion proceeded for $24 \mathrm{~h}$, after which the membranes were fixed and Giemsa-stained. The cell numbers were determined in three random microscopic fields of $x 400$ magnification for each well, with the means of nine values from triplicate experiments being used to quantify invasion.

Cell proliferation assessment using MTT. The effect of Drosha knockdown (Drosha-KD) on cell growth was examined using a 3-(4,5-dimethylthiazol-2-yl)-2,5-diphenyltetrazolium bromide (MTT) assay. In total, $2 \times 10^{3}$ cells/well were plated in triplicate into a 96-well plate, and cell proliferation was assayed continuously for 5 days. At each time point, $20 \mu \mathrm{l}$ MTT reagent ( $5 \mathrm{mg} / \mathrm{ml}$ in PBS) was added to the well, followed by $4 \mathrm{~h}$ of incubation at $37^{\circ} \mathrm{C}$. The media were discarded, and $100 \mathrm{ml}$ of DMSO was then added to each well to dissolve the precipitate by incubating for $30 \mathrm{~min}$. The absorbance was measured at a wavelength of $490 \mathrm{~nm}$ using a Bio-Rad microplate reader.

Clone formation. For the colony-forming assay, 200 cells that were infected with Lenti-shDro or Lenti-NC were seeded in a 6-well plate and cultured for 2 weeks. Thereafter, the media was removed and Giemsa-stained. The cell colonies with $>1 \mathrm{~mm}$ diameter were counted after staining. The experiments were performed in triplicate using three cervical cancer cell lines (HeLa, SiHa and C33a).

Two-dimensional electrophoresis (2-DE) and mass spectrometry. 2-DE was performed as previously described (17). Isoelectric focusing (IEF) was performed using an IPGphor II apparatus (Amersham Biosciences, Arlington Heights, IL, USA). IPG strips (24 cm, $\mathrm{pH} 4.0-10.0$, nonlinear) were used according to the manufacturer's instructions. Samples that contained $500 \mu \mathrm{g}$ protein were diluted to $2 \mathrm{ml}$ in a rehydration solution (8 M urea, 2\% CHAPS, $0.4 \%$ DTT, $0.5 \%$ IPG buffer, $0.002 \%$ bromophenol blue). The rehydration step was performed with 24-cm IPG strips for $12 \mathrm{~h}$ at room temperature. IEF was run following a step-wise voltage increase procedure: 500 and $1,000 \mathrm{~V}$ for $1 \mathrm{~h}$ each followed by $8,000 \mathrm{~V}$ for $60 \mathrm{kVh}$. After IEF, the IPG gel strips were placed in an equilibration buffer (6 M urea, $2 \%$ SDS, 30\% glycerol, $0.002 \%$ bromophenol blue, $50 \mathrm{mM}$ Tris-HCl, pH 6.8) that contained 1\% DTT for 15 min under agitation. The IPG strips were then transferred to an equilibration solution that contained $2.5 \%$ iodoacetamide and shaken for an additional 15 min before being placed onto $12.5 \%$ uniform polyacrylamide gel slabs $(1.5 \mathrm{~mm})$. Separation in the second dimension was performed in Tris-glycine buffer (25 mM Tris, $0.2 \mathrm{M}$ glycine, 0.1\% SDS) at a constant current setting of $15 \mathrm{~mA} / \mathrm{gel}$ for $30 \mathrm{~min}$ and $30 \mathrm{~mA} / \mathrm{gel}$ thereafter. SDS-PAGE separation was terminated when the bromophenol dye front migrated to the lower end of the gels.

After 2-DE, the gels were stained by a modified Coomassie G-250 method that is compatible with downstream MS 

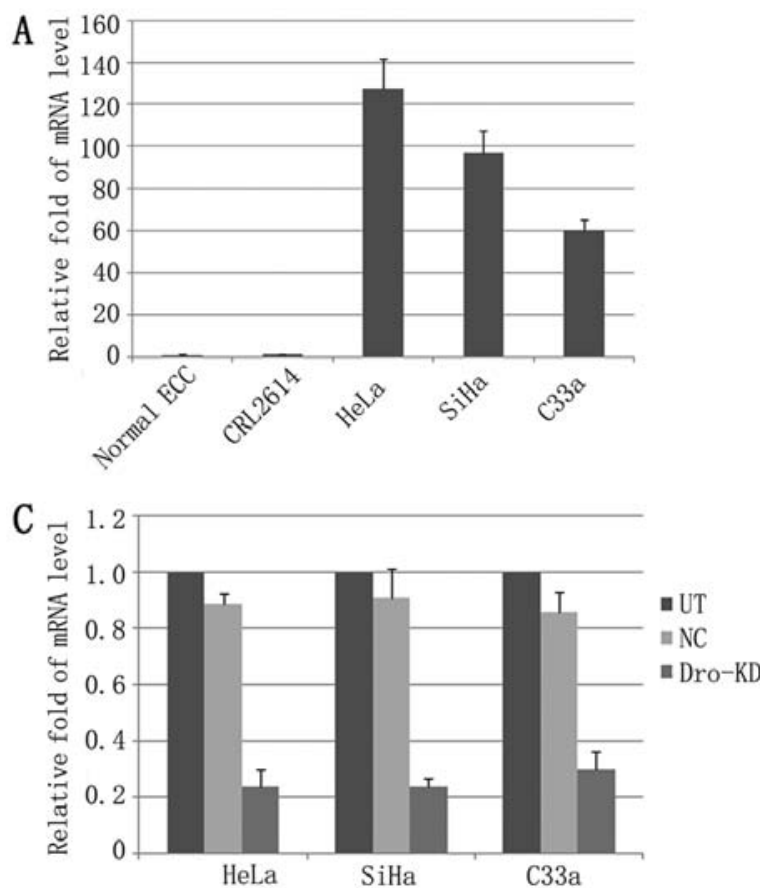

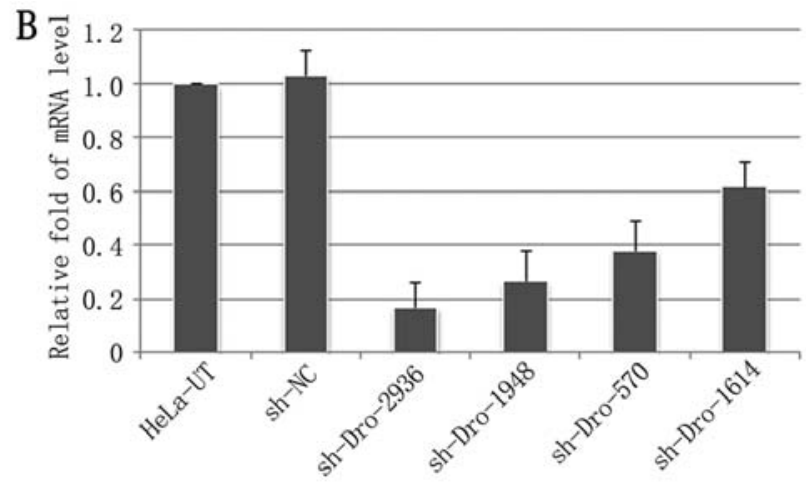

D

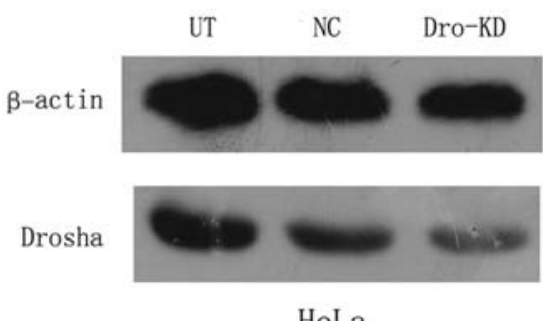

HeLa

Figure 1. Lentiviral vector-mediated downregulation of Drosha expression in cervical cancer cell lines. (A) Drosha expression was dramatically upregulated in the examined cervical cancer cell lines. The mRNA level of Drosha was determined using quantitative real-time PCR (qRT-PCR). (B) Four shRNAs targeting Drosha were transfected into HeLa cells, with shDro 2936 exhibiting the best knockdown efficiency. (C) Lenti-shDro 2936-mediated downregulation of Drosha in cervical cancer cells as revealed by qRT-PCR. Three cervical cancer cell lines were infected with a control vector (NC) or Lenti-shDro 2936 Drosha knockdown (Dro-KD). (D) Drosha was downregulated in HeLa cells infected by Lenti-shDro 2936, as confirmed by western blotting. UT, untreated.

analysis, as previously described (18). The entire staining procedure was performed over three days at room temperature with the gels gently shaken.

The raw images were digitised using a scanner (Amersham Biosciences). The images were further analysed using PDQuest (version 8.0; Bio-Rad). Twenty-one spots of interest were manually excised from the 2-DE gels and de-stained by washing with a mixture of $200 \mathrm{mM} \mathrm{NH} \mathrm{HCO}_{3}$ /acetonitrile (1:1). The proteins were reduced with DTT, alkylated with iodoacetamide, and digested in-gel with trypsin (Promega, Madison, WI, USA).

The peptides were lyophilised and subsequently dissolved in $2 \% \mathrm{ACN} / 0.1 \%$ formic acid. Each fraction was subjected to LC-MS analysis using a Nano HPLC (Eksigent) coupled to a Q-Star Elite mass spectrometer (Applied Biosystems). The peptides were first enriched using a CapTrap column $(0.5 \times 2 \mathrm{~mm}$; Michrom Bioresources, Inc.) followed by elution into an integrated nanoscale analytical column (Magic C18AQ; Michrom Bioresources, Inc.; $100 \mu \mathrm{m}$ x $150 \mathrm{~mm}, 3-\mu \mathrm{m}$ particle size, 200-^ pore size). We conducted each MS scan from 400 to $1,800 \mathrm{amu}$, with $1 \mathrm{sec}$ time spans. For the MS/MS analysis, each scan cycle consisted of one full-scan mass spectrum (with $\mathrm{m} / \mathrm{z}$ ranging from 400 to 1,800 and charge states from 2 to 5) followed by five MS/MS events. The threshold count was set to 30 , and the exclusion window was set at $90 \mathrm{sec}$. The mass tolerance was $50 \mathrm{mDa}$. The automatic collision energy and automatic MS/MS accumulation settings were selected.

The raw data from the Q-Star Elite mass spectrometer were analysed with Mascot Daemon software (version 2.2.2; Matrix Science) using a local Mascot engine. The data were searched against an NCBI database. Cysteine carbamidomethylation was set as a fixed modification, and methionine oxidation as well as serine, threonine, and tyrosine phosphorylation were set as variable modifications. The peptide mass tolerance was set at $200 \mathrm{ppm}$ and $0.4 \mathrm{Da}$. The peptide charge was set at $2^{+}$and $3^{+}$, allowing for up to two missed cleavages, and the significance threshold was set at $\mathrm{P}<0.05$.

Statistical analysis. The data are expressed as the mean \pm SD from at least three separate experiments performed in triplicate, unless otherwise noted. Significant differences between the groups were compared using the Student's t-test. A $\mathrm{P}$-value $<0.05$ was considered to indicate a statistically significant result.

\section{Results}

Lentiviral vector-mediated downregulation of Drosha in cervical cancer cells. The expression levels of Drosha were determined using qRT-PCR in the immortalised human normal cervical epithelial cell line CRL2614, three primary cultured normal cervical squamous cell lines and three cervical cancer cell lines (HeLa, SiHa and C33a). Drosha mRNA expression was upregulated $>60$-fold in the cervical cancer cell lines when compared to the normal cervical epithelial cells (Fig. 1A).

To identify an effective shRNA for Drohsa-KD, 4 shRNAs targeting Drosha were transfected into HeLa cells. Among these shDros, shDro homo 2936 downregulated Drosha the most significantly, with Drosha mRNA levels being reduced by $\sim 83 \%$ (Fig. 1B). We then established a Lenti-shDro using this shRNA. The lentiviral vector expressing shNC was used as a control. Over $95 \%$ of the cervical cancer cells that were 
A

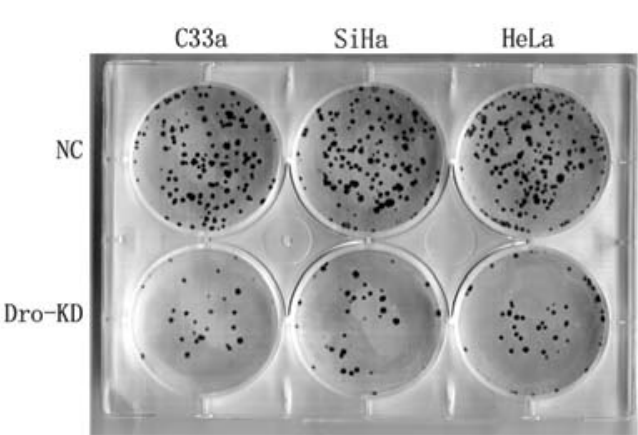

C

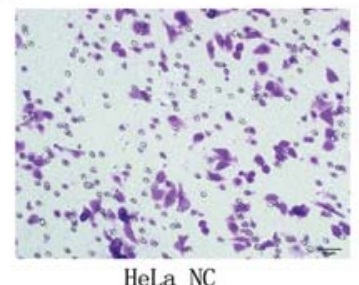

HeLa NC
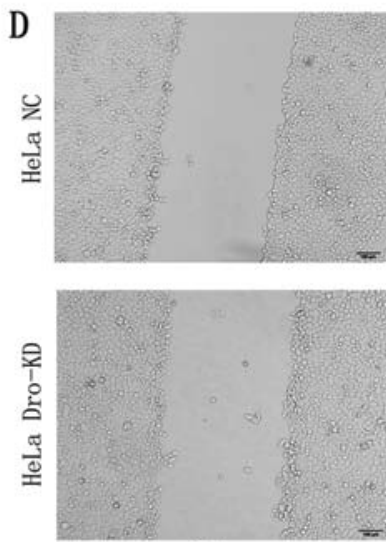

$0 \mathrm{~h}$

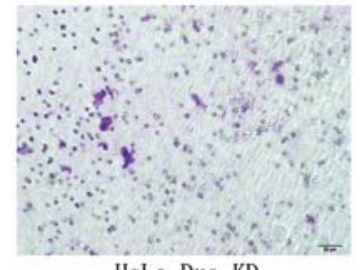

HeLa Dro-KD
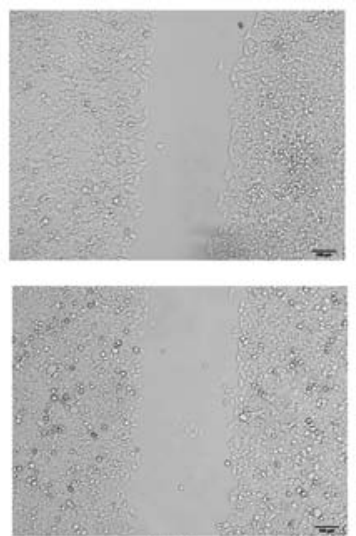

$24 \mathrm{~h}$
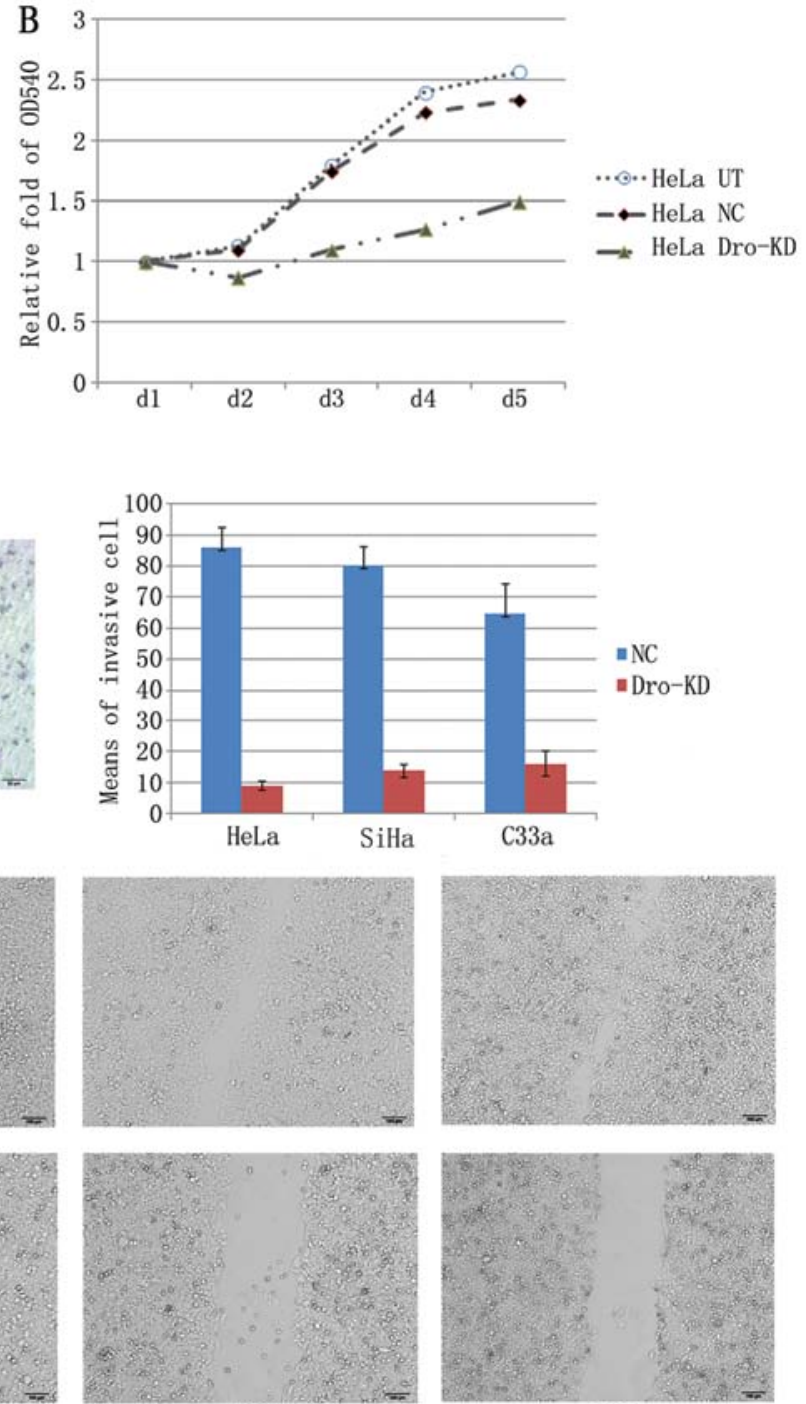

$48 \mathrm{~h}$

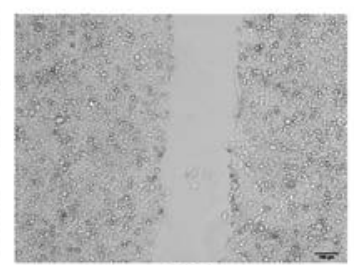

$72 \mathrm{~h}$

Figure 2. Drosha knockdown (Dro-KD) inhibits cervical cancer cell growth, invasion and migration. (A) The clone formation assay demonstrated that Dro-KD downregulated the clonogenicity of cervical cancer cells. (B) The MTT assay revealed a significantly slower growth of Dro-KD HeLa cells when compared to the NC or untreated (UT) HeLa cells. (C) Left panels: the results of the migration assays of HeLa cells with or without Dro-KD. Right panel: a histogram of the number of migratory HeLa, SiHa and C33a cells following infection with Lenti-shDro or Lenti-NC vectors. (D) Representative images of the wound-healing assays acquired at $0,24,48$ and $72 \mathrm{~h}$ showing decreased migration of HeLa cells with Dro-KD compared with the NCs.

transduced with Lenti-shDro or Lenti-shNC expressed GFP after puromycin screening, and the Drosha mRNA level was dramatically decreased $(\sim 80 \%)$ in cells that were infected with Lenti-shDro when compared with the Lenti-shNC cells (Fig. 1C). The Drosha-KD in HeLa cells was further confirmed by western blotting (Fig. 1D).

Downregulation of Drosha inhibits cervical cancer cell growth and migration. To investigate the biological effects of Drosha-KD in cervical cancer cells, we performed an MTT assay, a clone formation assay, a wound-healing test and a Transwell migration assay. The MTT assay revealed a significant inhibition of cell proliferation in HeLa cells with Drosha-KD (Fig. 2A). The cervical cancer cells lost their enhanced clonogenicity following Drosha-KD (Fig. 2B). Additionally, the results from the Transwell assay indicated that the migratory ability was reduced in HeLa, SiHa and C33a cells that were infected with the Lenti-shDro when compared with the NC cells (Fig 2C). The results of the wound-healing tests confirmed that the reduction in migration was mediated by Drosha-KD (Fig. 2D).

Drosha-KD alters the proteomic profile of human cervical cancer. Total protein extracted from transduced HeLa cells was used for 2-DE and subsequent mass spectrometry. PDQuest image analysis revealed an increase in global protein expression in Drosha-KD cells. Based on the data in the PDQuest report, the number of detectable spots in the gels of the Drosha-KD cells was significantly higher than the number in the NC cells $(417 \pm 16.6$ vs. $247 \pm 70.2 ; \mathrm{P}=0.015)$. Sixty-nine spots were detected only in the Drosha-KD gels, and only five spots were observed in the NC cell gels.

Tubulin $5 \beta$ is a potential target of Drosha. Twenty-one protein spots with at least a 3 -fold change were chosen for protein identification by liquid chromatography and tandem mass 


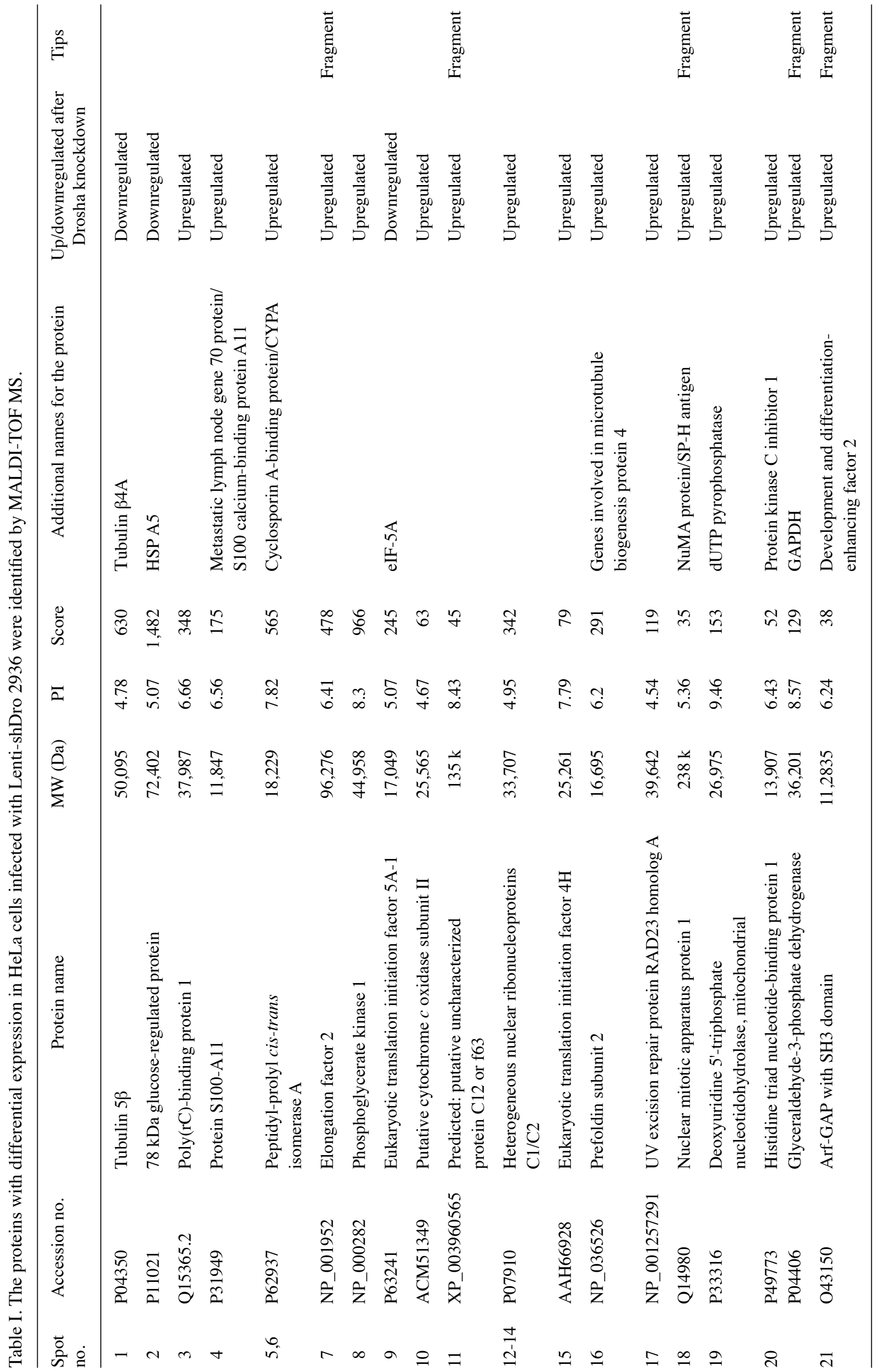


Table II. Associated disease and function of MS identified proteins.

\begin{tabular}{lll}
\hline Spot & Protein name & Associated disease (refs.)
\end{tabular}

1 Tubulin $5 \beta \quad$ Human cancer $(19,20)$

$2 \quad 78 \mathrm{kDa}$ glucose-regulated protein

3 Poly(rC)-binding protein 1

4 Protein S100-A11

5,6 Peptidyl-prolyl cis-trans isomerase $\mathrm{A}$

7 Elongation factor 2

8 Phosphoglycerate kinase 1

9 Eukaryotic translation initiation factor 5A-1

10 Putative cytochrome $c$ oxidase subunit II

11 Predicted: putative uncharacterized protein $\mathrm{C} 12$ or $\mathrm{f} 63$

12-14 Heterogeneous nuclear ribonucleoproteins $\mathrm{C} 1 / \mathrm{C} 2$

15 Eukaryotic translation initiation factor $4 \mathrm{H}$

16 Prefoldin subunit 2

17 UV excision repair protein RAD23 homolog A

18 Nuclear mitotic apparatus protein 1

19 Deoxyuridine 5'-triphosphate nucleotidohydrolase

20 Histidine mitochondrial nucleotide-binding protein 1 Glyceraldehyde-3-phosphate dehydrogenase

21 Arf-GAP with SH3 domain
Breast cancer (22), endometrial cancer (23)

Viral infection (24), human hepatoma (25)

Lung cancer (26), breast carcinoma (27)

Viral infection (28), hepatocellular carcinoma (29)

Lung adenocarcinoma (30), gastrointestinal cancers (31)

Prostate tumour (32), gastric cancer (33)

Lung cancer (34), hepatocellular carcinoma (35)

No report

No report

No report

Colorectal cancer (37)

No report

Gene disease (38)

Epithelial ovarian cancers (39), breast cancer (40)

No report

Melanoma (42), gastric cancer (43) Colon cancer (44), ovarian cancer (45)

Breast cancer (47), colorectal cancer (48)
Required for mitosis, limited cell proliferation (21), increases following treatment with chemotherapeutic agents $(19,20)$

Sensitises tumour cells to chemotherapy $(22,23)$

Antiviral immunity and prevention of inflammation (24)

Cell proliferation (26), a diagnostic marker in breast carcinoma (27)

Diverse roles in viral infection (28), promotes HCC cell metastasis (29)

Anti-apoptotic marker (30), promotes G2/M progression and enhanced cell growth (31)

Promotes tumour cell growth, supports the interactions between cancer and its microenvironment (32), a potential marker for peritoneal dissemination (33)

Prognostic marker $(34,35)$

No report

No report

Maintenance of cellular homeostasis besides cellular differentiation and proliferation (36)

Activates cyclin D1 (37)

No report

Gene environment interaction, cell cycle control and protein ubiquitination (38)

Highly expressed in EOC (39), spindle assembly (41)

No report

Tumour suppressor, inhibits the Wnt/ $\beta$-catenin pathway (42)

Associated with energy metabolism and production, cell proliferation and tumourigenesis (46)

Promotes tumour cell motility and invasiveness, stimulates metastasis formation $(47,48)$ spectrometry technology (LC-MS/MS) analysis. Eighteen proteins were ultimately identified (Table I). The associated diseases and functions of these proteins are summarised in
Table II. Twelve of these proteins are associated with human tumours. As revealed by the 2-DE data, the tubulin $5 \beta$ spot had the highest-ranked change after Drosha-KD. Functionally, 
A

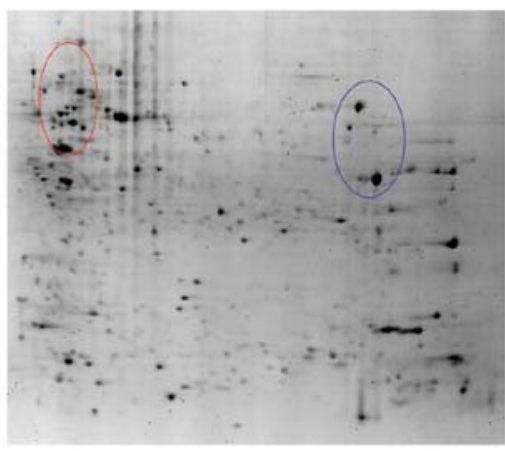

HeLa NC

B

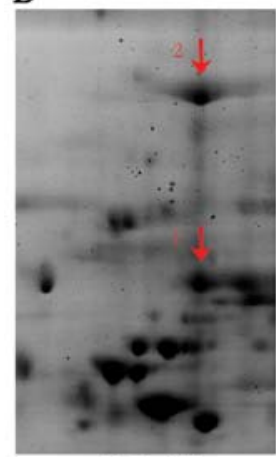

HeLa NC

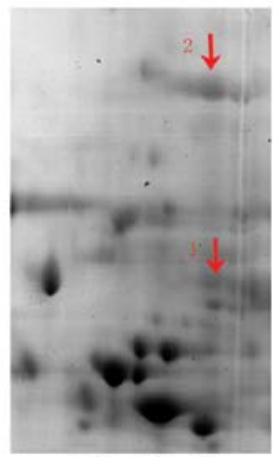

HeLa Dro-KD
$\mathrm{C}$

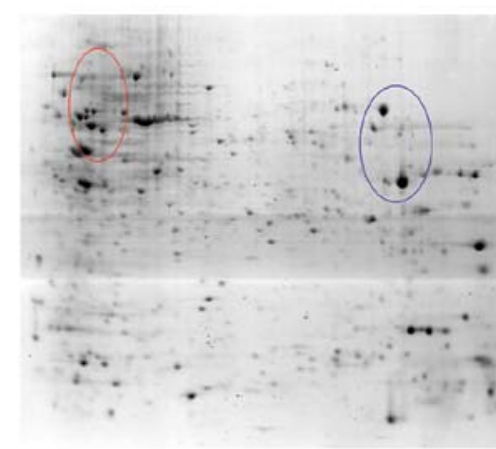

HeLa Dro-KD

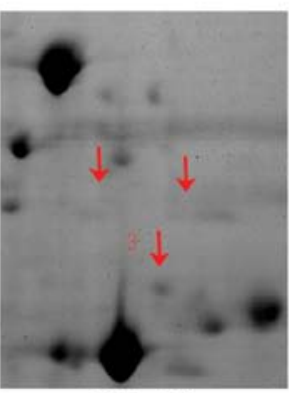

HeLa NC

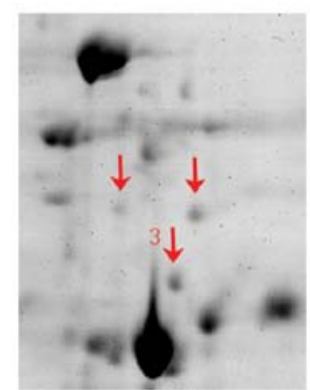

HeLa Dro-KD

D

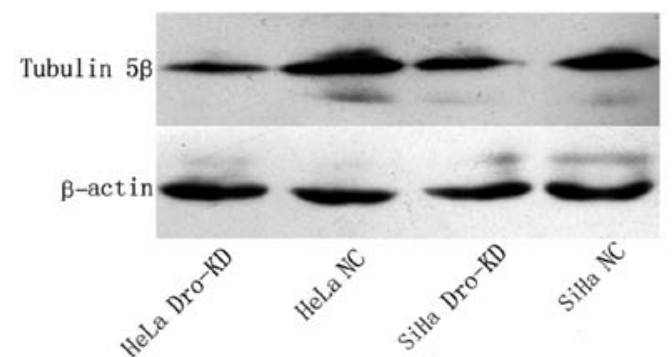

Figure 3. Drosha knockdown (Dro-KD) alters the protein profile of HeLa cells. (A) Overview of two-dimensional gel electrophoresis (2-DE) gels of HeLa cells that were infected with Lenti-shDro or Lenti-NC revealed that the downregulation of Drosha alters the protein expression profile. (B) Detailed views of the red oval area in A show spots with significantly decreased protein abundance (arrows). Spot 1, tubulin 5 $\beta$; Spot 2, glucose-regulated protein. (C) 2-D detailed view of the blue oval area in A. Several proteins (arrows) were significantly upregulated in the Dro-KD HeLa cells. Point 3, Poly(rc)-binding protein 1. (D) The Dro-KD-induced downregulation of tubulin $5 \beta$ was validated by western blotting in the HeLa and SiHa cell lines.

as an important component of the cytoskeleton, $\beta$-tubulin is associated with cell proliferation and the cell cycle and is a target of chemotherapeutic agents, such as paclitaxol.

To confirm the regulation of tubulin $5 \beta$ by Drosha, we next performed western blotting to detect tubulin $5 \beta$ protein expression in HeLa and $\mathrm{SiHa}$ cells that were transduced with the Lenti-shDro or Lenti-shNC. Our results found that Drosha-KD reduced the expression of tubulin $5 \beta$ in cervical cancer cells (Fig. 3D).

\section{Discussion}

It is well known that Drosha is one of the key enzymes involved in the maturation of miRNA, and the expression level of this gene is robustly associated with the miRNA profile (11). In the present study, for the first time, we demonstrated the significant influence of Drosha-KD on the proteomic profile.
Since as many as $60 \%$ of the human protein-coding genes are regulated by miRNA machinery (49), the last decade has seen an increasing number of studies that have focused on the function of miRNAs in cancer. For example, a global upregulation of miRNAs was observed in cervical cancer. Hence, the enzymes that affect miRNA genesis are becoming new and very popular areas of research. As a nuclear enzyme that initiates miRNA processing, Drosha regulates the expression of most miRNAs. In Drosha overexpressing cervical cancer cells, 45 microRNAs exhibited a significant association with Drosha levels. The majority of these miRNAs $(n=40,88.9 \%)$ were upregulated, with only five (11.1\%) being downregulated (11). In the present study, we determined that Drosha-KD altered the entire cell proteomic profile, an effect that can be explained by the potent biological functions of Drosha and miRNAs. Theoretically, the depletion of Drosha will decrease mature miRNA expression levels, reduce the suppression of proteins by miRNAs, and consequently alter protein expression. 
Notably, we observed that several proteins were upregulated after Drosha-KD, although the majority of the proteins with significantly altered abundance were downregulated. This result is well correlated with the alteration in miRNAs that results from Drosha overexpression that was observed by Balaji et al and suggests the complexity of the regulation of miRNA and protein expression.

We observed that Drosha-KD led to the suppression of cell proliferation, clonogenesis, and migration in cervical cancer, suggesting that a higher level of Drosha is associated with a more invasive tumour phenotype. This effect may potentially be due to the Drosha-KD-induced alteration in the proteomic profile, particularly in the expression of cancer-related proteins.

As a cornerstone of the microtubule system, $\beta$-tubulin plays an important role in mitosis, intracellular trafficking, migration and the maintenance of cell shape (50). The lack or alteration of $\beta$-tubulin can inhibit mitosis and cause cells to be delayed in the G2/M phase (51). Additionally, the importance of microtubules in mitotic spindle formation and chromosome movement during cell division makes microtubules a major target for chemotherapeutic drugs that are used to halt the uncontrolled division of cancer cells (52). Our findings suggest that Drosha may influence the response of tumours to drugs that target microtubules, such as paclitaxol, and could be used to treat bulky cervical cancer in combination with platinum as a neoadjuvant chemotherapy.

In conclusion, our study demonstrates that the upregulation of Drosha alters the proteomic profile of cervical cancer cells. Furthermore, tubulin- $\beta$ and the microtubule system are affected by Drosha expression.

\section{Acknowledgements}

This study was supported by the China Postdoctoral Science Foundation (grant no. 20100480904).

\section{References}

1. Yang W, Lee DY and Ben-David Y: The roles of microRNAs in tumorigenesis and angiogenesis. Int $\mathrm{J}$ Physiol Pathophysiol Pharmacol 3: 140-155, 2011.

2. Calin GA, Sevignani C, Dumitru CD, et al: Human microRNA genes are frequently located at fragile sites and genomic regions involved in cancers. Proc Natl Acad Sci USA 101: 2999-3004, 2004.

3. Krutzfeldt J, Rajewsky N, Braich R, et al: Silencing of microRNAs in vivo with 'antagomirs'. Nature 438: 685-689, 2005.

4. Esquela-Kerscher A and Slack FJ: Oncomirs - microRNAs with a role in cancer. Nat Rev Cancer 6: 259-269, 2006

5. Lee Y, Ahn C, Han J, et al: The nuclear RNase III Drosha initiates microRNA processing. Nature 425: 415-419, 2003.

6. Bernstein E, Caudy AA, Hammond SM and Hannon GJ: Role for a bidentateribonuclease in the initiation step of RNA interference. Nature 409: 363-366, 2001.

7. Macrae IJ,Zhou K, Li F, et al: Structural basis for double-stranded RNA processing by Dicer. Science 311: 195-198, 2006.

8. Atkin NB: Cytogenetics of carcinoma of the cervix uteri: a review. Cancer Genet Cytogenet 95: 33-39, 1997.

9. Heselmeyer K, Macville M, Schrock E, et al: Advanced-stage cervical carcinomas are defined by a recurrent pattern of chromosomal aberrations revealing high genetic instability and a consistent gain of chromosome arm 3q. Genes Chromosomes Cancer 19: 233-240, 1997.

10. Kirchhoff M, Rose H, Petersen BL, et al: Comparative genomic hybridization reveals a recurrent pattern of chromosomal aberrations in severe dysplasia/carcinoma in situ of the cervix and in advanced-stage cervical carcinoma. Genes Chromosomes Cancer 24: 144-150, 1999.
11. Muralidhar B, Winder D, Murray M, et al: Functional evidence that Drosha overexpression in cervical squamous cell carcinoma affects cell phenotype and microRNA profiles. J Pathol 224: 496-507, 2011.

12. Muralidhar B, Goldstein LD, Ng G, et al: Global microRNA profiles in cervical squamous cell carcinoma depend on Drosha expression levels. J Pathol 212: 368-377, 2007.

13. Pett MR, Alazawi WO, Roberts I, et al: Acquisition of high-level chromosomal instability is associated with integration of human papillomavirus type 16 in cervical keratinocytes. Cancer Res 64: 1359-1368, 2004.

14. Pett MR, Herdman MT, Palmer RD, et al: Selection of cervical keratinocytes containing integrated HPV16 associates with episome loss and an endogenous antiviral response. Proc Natl Acad Sci USA 103: 3822-3827, 2006.

15. Boudreau RL, Spengler RM and Davidson BL: Rational design of therapeutic siRNAs: minimizing off-targeting potential to improve the safety of RNAi therapy for Huntington's disease. Mol Ther 19: 2169-2177, 2011.

16. Cai J, Tang H, Xu L, Wang X, et al: Fibroblasts in omentum activated by tumor cells promote ovarian cancer growth, adhesion and invasiveness. Carcinogenesis 33: 20-29, 2012.

17. Diao S, Zhang JF, Wang $\mathrm{H}$, et al: Proteomic identification of microRNA-122a target proteins in hepatocellular carcinoma. Proteomics 10: 3723-3731, 2010.

18. Dyballa N and Metzger S: Fast and sensitive colloidal Coomassie G-250 staining for proteins in polyacrylamide gels. J Vis Exp 30: pii1431, 2009.

19. Wiesen KM, Xia S, Yang CP and Horwitz SB: Wild-type class I beta-tubulin sensitizes Taxol-resistant breast adenocarcinoma cells harboring a beta-tubulin mutation. Cancer Lett 257: 227-235, 2007.

20. Schmidt M, Schler G, Gruensfelder P and Hoppe F: Differential gene expression in a paclitaxel-resistant clone of a head and neck cancer cell line. Eur Arch Otorhinolaryngol 263: 127-134, 2006.

21. Akoumianaki T, Kardassis D, Polioudaki H, et al: Nucleocyto plasmic shuttling of soluble tubulin in mammalian cells. J Cell Sci 122: 1111-1118, 2009

22. Li C, Harada A and Oh Y: IGFBP-3 sensitizes antiestrogenresistant breast cancer cells through interaction with GRP78. Cancer Lett 325: 200-206, 2012.

23. Luvsandagva B, Nakamura K, Kitahara Y, et al: GRP78 induced by estrogen plays a role in the chemosensitivity of endometrial cancer. Gynecol Oncol 126: 132-139, 2012.

24. Zhou X, You F, Chen H and Jiang Z: Poly(C)-binding protein 1 (PCBP1) mediates housekeeping degradation of mitochondrial antiviral signaling (MAVS). Cell Res 22: 717-727, 2012.

25. Lian WX, Yin RH, Kong XZ, et al: THAP11, a novel binding protein of $\mathrm{PCBP} 1$, negatively regulates $\mathrm{CD} 44$ alternative splicing and cell invasion in a human hepatoma cell line. FEBS Lett 586: 1431-1438, 2012.

26. Hao J, Wang K, Yue Y, et al: Selective expression of S100A11 in lung cancer and its role in regulating proliferation of adenocarcinomas cells. Mol Cell Biochem 359: 323-332, 2012.

27. Liu XG, Wang XP, Li WF, et al: $\mathrm{Ca}^{2+}$-binding protein S100A11: A novel diagnostic marker for breast carcinoma. Oncol Rep 23: 1301-1308, 2010.

28. Zhou D, Mei Q, Li J and He H: Cyclophilin A and viral infections. Biochem Biophys Res Commun 424: 647-650, 2012.

29. Zhang M, Dai C, Zhu H, et al: Cyclophilin A promotes human hepatocellular carcinoma cell metastasis via regulation of MMP3 and MMP9. Mol Cell Biochem 357: 387-395, 2011.

30. Chen CY, Fang HY, Chiou SH, et al: Sumoylation of eukaryotic elongation factor 2 is vital for protein stability and anti-apoptotic activity in lung adenocarcinoma cells. Cancer Sci 102: 1582-1589, 2011.

31. Nakamura J, Aoyagi S, Nanchi I, et al: Overexpression of eukaryotic elongation factor eEF2 in gastrointestinal cancers and its involvement in $\mathrm{G} 2 / \mathrm{M}$ progression in the cell cycle. Int J Oncol 34: 1181-1189, 2009.

32. Wang J, Ying G, Wang J, et al: Characterization of phosphoglycerate kinase-1 expression of stromal cells derived from tumor microenvironment in prostate cancer progression. Cancer Res 70: 471-480, 2010.

33. Zieker D, Königsrainer I, Tritschler I, et al: Phosphoglycerate kinase 1 a promoting enzyme for peritoneal dissemination in gastric cancer. Int J Cancer 126: 1513-1520, 2010.

34. He LR, Zhao HY, Li BK, et al: Overexpression of eIF5A-2 is an adverse prognostic marker of survival in stage I non-small cell lung cancer patients. Int J Cancer 129: 143-150, 2011. 
35. Lee NP, Tsang FH, Shek FH, et al: Prognostic significance and therapeutic potential of eukaryotic translation initiation factor $5 \mathrm{~A}$ (eIF5A) in hepatocellular carcinoma. Int J Cancer 127: 968-976, 2010.

36. Hossain MN, Fuji M, Miki K, Endoh M and Ayusawa D: Downregulation of hnRNP C1/C2 by siRNA sensitizes HeLa cells to various stresses. Mol Cell Biochem 296: 151-157, 2007.

37. Wu D, Matsushita K, Matsubara $H$, Nomura F and Tomonaga T: An alternative splicing isoform of eukaryotic initiation factor $4 \mathrm{H}$ promotes tumorigenesis in vivo and is a potential therapeutic target for human cancer. Int J Cancer 128: 1018-1030, 2011.

38. Bailey SD, Xie C, Do R, et al: Variation at the NFATC2 locus increases the risk of thiazolidinedione-induced edema in the Diabetes REduction Assessment with ramipril and rosiglitazone Medication (DREAM) study. Diabetes Care 33: 2250-2253, 2010.

39. Brüning-Richardson A, Bond J, Alsiary R, et al: NuMA overexpression in epithelial ovarian cancer. PLoS One 7: e38945, 2012.

40. Kilpivaara O, Rantanen M, Tamminen A, et al: Comprehensive analysis of NuMA variation in breast cancer. BMC Cancer 8: 71, 2008.

41. Chang P, Coughlin M and Mitchison TJ: Interaction between Poly(ADP-ribose) and NuMA contributes to mitotic spindle pole assembly. Mol Biol Cell 20: 4575-4585, 2009.

42. Genovese G, Ghosh P, Li H, et al: The tumor suppressor HINT1 regulates MITF and $\beta$-catenin transcriptional activity in melanoma cells. Cell Cycle 11: 2206-2215, 2012.

43. Huang H, Wei X, Su X, et al: Clinical significance of expression of Hint 1 and potential epigenetic mechanism in gastric cancer Int J Oncol 38: 1557-1564, 2011.

44. Tang Z, Yuan S, Hu Y, et al: Over-expression of GAPDH in human colorectal carcinoma as a preferred target of 3-bromopyruvate propyl ester. J Bioenerg Biomembr 44: 117-125, 2012.
45. Huang Q, Lan F, Zheng Z, et al: Akt2 kinase suppresses glyceraldehyde-3-phosphate dehydrogenase (GAPDH)-mediated apoptosis in ovarian cancer cells via phosphorylating GAPDH at threonine 237 and decreasing its nuclear translocation. J Biol Chem 286: 42211-42220, 2011.

46. Nicholls C, Li H and Liu JP: GAPDH: a common enzyme with uncommon functions. Clin Exp Pharmacol Physiol 39: 674-679, 2012.

47. Hashimoto S, Hirose M, Hashimoto A, et al: Targeting AMAP1 and cortactin binding bearing an atypical src homology 3/proline interface for prevention of breast cancer invasion and metastasis. Proc Natl Acad Sci USA 103: 7036-7041, 2006.

48. Müller T, Stein U, Poletti A, et al: ASAP1 promotes tumor cell motility and invasiveness, stimulates metastasis formation in vivo, and correlates with poor survival in colorectal cancer patients. Oncogene 29: 2393-2403, 2010.

49. Friedman RC, Farh KK, Burge CB and Bartel DP: Most mammalian mRNAs are conserved targets of microRNAs. Genome Res 19: 92-105, 2009.

50. Shibazaki M, Maesawa C, Akasaka K, et al: Transcriptional and post-transcriptional regulation of $\beta$ III-tubulin protein expression in relation with cell cycle-dependent regulation of tumor cells. Int J Oncol 40: 695-702, 2012.

51. Nogales E: Structural insights into microtubule function. Annu Rev Biochem 69: 277-302, 2000.

52. Jordan MA and Wilson L: Microtubules as a target for anticancer drugs. Nat Rev Cancer 4: 253-265, 2004. 